\title{
Frequency and associated risk factors of non-fatal overdose reported by pregnant women with opioid use disorder
}

\author{
Sarah M. Bagley ${ }^{1,2^{*}}$, Howard Cabral ${ }^{3}$, Kelley Saia ${ }^{4}$, Alyssa Brown ${ }^{5}$, Christine Lloyd-Travaglini ${ }^{3}$, Alexander Y. Walley ${ }^{1}$ \\ and Ruth Rose-Jacobs ${ }^{2}$
}

\begin{abstract}
Background: Little is known about opioid overdose or naloxone access among pregnant women.

Objectives: The objectives of this study were to determine the prevalence of non-fatal overdose, risk factors for overdose, and naloxone access among third trimester women in treatment for opioid use disorder.

Methods: We collected baseline data from a case management parental-support intervention study. To explore the association of variables with past year overdose, we used Wilcoxon rank-sum test, Chi square or Fisher's exact tests.

Results: Among 99 participants, 14\% (95\% Cl 7-21\%) reported past year overdose and 67\% (95\% Cl 57-76\%) had received overdose education and a naloxone kit. Younger age was the only variable associated with past year overdose.

Conclusions: In this sample, past year non-fatal overdose was common, younger age was a risk factor, and most participants had received a naloxone kit. Further work is needed to understand whether younger age is a risk factor in the general population of pregnant women with opioid use disorder and to identify other potential risk factors for overdose in this population.
\end{abstract}

Keywords: Opioids, Overdose, Pregnancy, Naloxone

\section{Introduction}

Opioid use disorder among pregnant women quadrupled from 1999 to 2014 [5] and between 2004 and 2013, the incidence of neonatal intensive care unit admissions for neonatal abstinence syndrome increased from 7 cases to 27 cases per 1000 admissions per year [8]. This evidence of increased burden of the opioid epidemic on pregnant women has paralleled an increase in opioid-related overdose deaths among women that has been faster than among men [3, 6]. Recent research in Massachusetts demonstrated that $2.3 \%$ of newborns were delivered to women with opioid use disorder and detailed the falling and rising risk of opioid overdose across pregnancy

\footnotetext{
*Correspondence: sarah.bagley@bmc.org

1 Department of Medicine, Boston University School of Medicine, Boston Medical Center, Boston, MA 02118, USA

Full list of author information is available at the end of the article
}

and post-partum periods [9]. Little is known about risk factors for overdose during pregnancy. Naloxone access, however, is a key strategy in addressing rising opioidrelated overdose deaths for all populations in the United States [2]. The objectives of this study were to determine the prevalence of reported non-fatal overdose, identify risk factors for overdose, and describe naloxone access in a sample of third trimester pregnant women in treatment for opioid use disorder.

\section{Methods}

We collected baseline data from a randomized controlled trial of a case management parental support intervention among pregnant women with opioid use disorders. Participants were recruited at an urban, academic obstetrics clinic specializing in pregnant women with substance use disorder. Maternal inclusion criteria were: treatment with methadone or buprenorphine, prenatal care and intent to 
deliver at our academic center, due date within 3 months of enrollment, $\geq 18$ years, singleton pregnancy, not incarcerated, ability to give consent, and intent to stay in area after delivery. Women planning to relinquish custody after delivery were excluded. Only women who met inclusion criteria for the intervention trial had baseline information collected.

The questionnaire, administered in the third trimester, prior to randomization, included demographics, major mental health diagnoses (depression, panic attacks/anxiety disorder, bipolar disorder, schizophrenia, post-traumatic stress disorder), opioid overdose history and naloxone access. Overdose history was determined by asking, "Have you ever overdosed?" and if positive: "In the past year, how many times have you overdosed? Naloxone access was determined by asking: "Have you ever received an overdose rescue kit that includes Narcan to use JUST IN CASE of an overdose?" and "Where did you receive the overdose rescue kit?"

The study was approved by the Boston University Medical Center Institutional Review Board and is registered at clinicaltrials.gov NCT02334111.

Using SAS 9.3 to explore the association of variables with past year overdose and no past year overdose, we conducted a Wilcoxon rank-sum test for continuous variables and Chi square or Fisher's exact tests for categorical variables. We combined the "no past year overdose" and "never overdosed" categories to one "no past year overdose" category because those participants would not have had an overdose during pregnancy.

\section{Results}

One hundred participants were recruited to the intervention study, however, one had missing overdose data and was not included in the analysis. The mean age was 28.5 years, $83 \%$ had at least a high school education, $73 \%$ were White/non-Hispanic, $82 \%$ were married or in a relationship, $74 \%$ were unemployed and $86 \%$ reported a major mental health diagnosis.

Among participants, 14\% reported past year overdose; $30 \%$ reported lifetime overdose history (but no past year overdose), and 56\% reported no overdose history. In the comparisons of past year overdose to no past year overdose, the only significant association with past year overdose was younger maternal age $(p=0.0081)$ (Table 1). Notably, of the 14 women who reported a past year overdose, all reported a major mental illness diagnosis. Of those with no past year overdose, $84 \%(n=71)$ reported a major mental illness diagnosis. Among those who overdosed in the past year, the median number of reported overdoses during that time was one, and the maximum number was seven.

Sixty-seven percent (95\% CI $57-76 \%)$ of participants had ever received a naloxone rescue kit (Table 1). Naloxone sources included inpatient detoxification programs $(n=28)$, needle exchanges $(n=16)$, friends/ acquaintances $(n=10)$, methadone programs $(n=10)$, emergency departments $(n=4)$, and drop-in centers $(\mathrm{n}=4)$.

\section{Table 1 Baseline characteristics of pregnant women with opioid use disorders stratified by past year overdose history}

\begin{tabular}{|c|c|c|c|c|}
\hline Variable & $\begin{array}{l}\text { Total } \mathrm{N}=99 \\
(95 \% \mathrm{Cl})\end{array}$ & $\begin{array}{l}\text { Overdose within last year } \\
n=14 \\
(95 \% \mathrm{Cl})\end{array}$ & $\begin{array}{l}\text { No past year overdose } \\
n=85 \\
(95 \% \mathrm{Cl})\end{array}$ & $p$ Value \\
\hline Mean maternal age & $\begin{array}{l}28.5 \\
(27.5-29.5)\end{array}$ & $\begin{array}{l}25.2 \\
(23.0-27.4)\end{array}$ & $\begin{array}{l}29.0 \\
(28.0-30.1)\end{array}$ & $0.0081^{*}$ \\
\hline White/non-hispanic & $\begin{array}{l}72(72.7 \%) \\
(64.0-81.5 \%)\end{array}$ & $\begin{array}{l}13(92.9 \%) \\
(79.4-100.0 \%)\end{array}$ & $\begin{array}{l}59(69.4 \%) \\
(59.6-79.2 \%)\end{array}$ & 0.1038 \\
\hline Married/in a relationship & $\begin{array}{l}81(81.8 \%) \\
(74.2 \%, 89.4 \%)\end{array}$ & $\begin{array}{l}11(78.6 \%) \\
(57.1 \%, 100.0 \%)\end{array}$ & $\begin{array}{l}70(82.4 \%) \\
(74.3 \%, 90.5 \%)\end{array}$ & 0.7152 \\
\hline Public insurance & $\begin{array}{l}92(92.9 \%) \\
(87.9 \%, 98.0 \%)\end{array}$ & $\begin{array}{l}12(85.7 \%) \\
(67.4 \%, 100.0 \%)\end{array}$ & $\begin{array}{l}80(94.1 \%) \\
(89.1 \%, 99.1 \%)\end{array}$ & 0.2572 \\
\hline Age at opioid initiation & $\begin{array}{l}20.2 \\
(19.2-21.1)\end{array}$ & $\begin{array}{l}18.3 \\
(17.2-19.4)\end{array}$ & $\begin{array}{l}20.5 \\
(19.4-21.6)\end{array}$ & 0.1227 \\
\hline Any history of mental health diagnosis & $\begin{array}{l}85(85.9 \%) \\
(79.0-92.7 \%)\end{array}$ & $\begin{array}{l}14(100.0 \%) \\
(100.0-100.0 \%)\end{array}$ & $\begin{array}{l}71(83.5 \%) \\
(75.6-91.4 \%)\end{array}$ & 0.2084 \\
\hline $\begin{array}{l}\text { Number of mental health } \\
\text { diagnoses }\end{array}$ & $\begin{array}{l}2.4 \\
(2.1-2.7)\end{array}$ & $\begin{array}{l}3.0 \\
(2.2-3.8)\end{array}$ & $\begin{array}{l}2.3 \\
(2.0-2.6)\end{array}$ & 0.1049 \\
\hline 2 or More mental health diagnoses & $\begin{array}{l}72(72.7 \%) \\
(64.0-81.5 \%)\end{array}$ & $\begin{array}{l}12(85.7 \%) \\
(67.4-100.0 \%)\end{array}$ & $\begin{array}{l}60(70.6 \%) \\
(60.9-80.3 \%)\end{array}$ & 0.3389 \\
\hline Ever received a naloxone kit & $\begin{array}{l}66(66.7 \%) \\
(57.4-76.0 \%)\end{array}$ & $\begin{array}{l}11(78.6 \%) \\
(57.1-100.0 \%)\end{array}$ & $\begin{array}{l}55(64.7 \%) \\
(54.6-74.9 \%)\end{array}$ & 0.3742 \\
\hline
\end{tabular}

*Significant result 


\section{Discussion}

About 1 in 7 pregnant women treated for an opioid use disorder reported a past year overdose. Younger age was associated with greater risk of past year overdose compared to no past year overdose. As far as we know, finding of younger age associated with past overdose in pregnant women has not previously been documented in the literature. This study found that $100 \%(n=14)$ of women with an overdose in the past year and $84 \%(n=71)$ of women with no past year overdose self-reported a major mental health diagnosis. This is consistent with other research findings that substance use may be used to relieve the symptoms associated with mental health disorders [7].

The majority of the sample had previously received a naloxone rescue kit, reflecting increased community access, although with the continued increase in opioidrelated deaths there is still room for improvement. In Massachusetts, where this study was conducted, overdose education and naloxone (OEND) access was common at many addiction treatment, harm reduction, and healthcare venues, but was not a specific component of the intervention offered in this study [12]. OEND has been incorporated into settings where recruitment for this study occurred, such as medication treatment programs.

Prior work has shown that detoxification centers, prisons and other abstinence-based treatment programs present an excellent opportunity to train individuals on use and distribute naloxone rescue kits before release [1, 11]. Pregnancy provides another opportunity to target this high-risk population. Pregnant women, motivated by their pregnancy, are engaged in the health care system and may be more receptive to education and prevention messages $[4,10]$. In addition, although it is common to focus on recovery during pregnancy, relapses and overdoses can occur. This study highlights that pregnant women are another group at risk for overdose and should be offered and have access to OEND. Since this population is most likely receiving prenatal care, obstetricians and other providers caring for this population should incorporate OEND into their services.

Study limitations included small sample size, and a reliance on self-reported data. The dates of overdose events were not collected. Because the window we asked about for overdose was 12 months and all the participants were in the third trimester of their pregnancies, we do not know if overdose occurred during or before pregnancy, and whether overdose might have been a factor in the decision to seek substance use disorder treatment. In addition, because baseline information was collected during the third trimester of pregnancy among women intending to retain custody, participants may have underreported their overdose history.
Our findings support targeted overdose prevention efforts among pregnant women with opioid use disorder that include naloxone rescue kits. Further research in this high-risk population, including understanding why younger maternal age may be a particular risk factor, is warranted.

\section{Authors' contributions}

SMB conceived of the study, interpreted the results, and wrote the first draft of the manuscript. $\mathrm{HC}$ was responsible for the analytic plan, interpretation of results, and reviewed the final draft of the manuscript. KS was responsible for conceiving of the study and review of the manuscript. AB conducted the literature review for the manuscript, helped with the interpretation of the results. CLT conducted the analysis and reviewed the final draft of the manuscript. AYW and RRJ helped to obtain funding and oversee data collection for the larger intervention study, conceive of the study, interpret results, and provided significant feedback and review of the manuscript. All authors read and approved the final manuscript.

\section{Author details}

${ }^{1}$ Department of Medicine, Boston University School of Medicine, Boston Medical Center, Boston, MA 02118, USA. ${ }^{2}$ Department of Pediatrics, Boston University School of Medicine, Boston Medical Center, Boston, MA 02118, USA. ${ }^{3}$ School of Public Health, Boston University, Boston, USA. ${ }^{4}$ Department of Obstetrics and Gynecology, Boston University School of Medicine, Boston Medical Center, Boston, USA. ${ }^{5}$ Northeastern University School of Public Health, Boston, USA.

\section{Acknowledgements}

Not applicable.

\section{Competing interests}

The authors declare that they have no competing interests.

\section{Availability of data}

The datasets used and/or analyzed during the current study are available from the corresponding author on reasonable request.

\section{Consent for publication \\ Not applicable.}

\section{Ethics approval}

This study was approved by the Boston University Medical Campus IRB.

Funding

Dr. Bagley receives salary support through NIDA 1K23DA044324; Abandoned Infants Assistance Program 90CB0186) division of US Department of Health and Human Services (PI: Dr. Rose-Jacobs).

\section{Publisher's Note}

Springer Nature remains neutral with regard to jurisdictional claims in published maps and institutional affiliations.

Received: 11 July 2018 Accepted: 29 November 2018

Published online: 14 December 2018

\section{References}

1. Bird SM, McAuley A, Perry S, Hunter C. Effectiveness of Scotland's National Naloxone Programme for reducing opioid-related deaths: a before (200610) versus after (2011-13) comparison. Addiction. 2016;111(5):883-91. https://doi.org/10.1111/add.13265.

2. Department of Health and Human Services. (2015). Opioid abuse in the U.S. and HHS actions to address opioid-drug related overdoses and deaths.

3. Desai RJ, Hernandez-Diaz S, Bateman BT, Huybrechts KF. Increase in prescription opioid use during pregnancy among Medicaid-enrolled 
women. Obstet Gynecol. 2014;123(5):997-1002. https://doi.org/10.1097/ AOG.00000000000000208.

4. Edvardsson K, Ivarsson A, Eurenius E, Garvare R, Nyström ME, Small $R$, Mogren I. Giving offspring a healthy start: parents' experiences of health promotion and lifestyle change during pregnancy and early parenthood. BMC Public Health. 2011;11(1):936. https://doi. org/10.1186/1471-2458-11-936.

5. Haight SC, Ko JY, Tong VT, Bohm MK, Callaghan WM. Opioid use disorder documented at delivery hospitalization-United States, 1999-2014. Morb Mortal Wkly Rep. 2018;67(31):845.

6. Mack KA, Jones CM, Paulozzi LJ. Vital signs: overdoses of prescription opioid pain relievers and other drugs among women — United States, 1999-2010. MMWR. 2013;62(26):537-42.

7. McHugh RK, DeVito EE, Dodd D, Carroll KM, Potter JS, Greenfield SF, et al. Gender differences in a clinical trial for prescription opioid dependence. J Subst Abuse Treat. 2013;45(1):38-43. https://doi.org/10.1016/j.jsat2 012.12.007.

8. Patrick SW, Davis MM, Lehmann CU, Cooper WO. Increasing incidence and geographic distribution of neonatal abstinence syndrome:
United States 2009 to 2012. J Perinatol. 2015;35(8):650-5. https://doi. org/10.1038/jp.2015.36.

9. Schiff DM, Nielsen T, Terplan M, Hood M, Bernson D, Diop H, et al. Fatal and nonfatal overdose among pregnant and postpartum women in Massachusetts. Obstet Gynecol. 2018;132(2):466-74. https://doi.org/10.1097/ AOG.0000000000002734.

10. Vonderheid SC, Norr KF, Handler AS. Prenatal health promotion content and health behaviors. West J Nurs Res. 2007;29(3):258-76. https://doi. org/10.1177/0193945906296568.

11. Walley AY, Doe-Simkins M, Quinn E, Pierce C, Xuan Z, Ozonoff A. Opioid overdose prevention with intranasal naloxone among people who take methadone. J Subst Abuse Treat. 2013;44(2):241-7. https://doi. org/10.1016/j.jsat.2012.07.004.

12. Walley AY, Xuan Z, Hackman H, Quinn E, Doe-Simkins M, SorensonAlawad A, Ruiz S. Opioid overdose rates and implementation of overdose education and nasal naloxone distribution in Massachusetts: interrupted time series analysis. BMJ. 2013;346:f174. https://doi.org/10.1136/bmj.f174.
Ready to submit your research? Choose BMC and benefit from:

- fast, convenient online submission

- thorough peer review by experienced researchers in your field

- rapid publication on acceptance

- support for research data, including large and complex data types

- gold Open Access which fosters wider collaboration and increased citations

- maximum visibility for your research: over 100M website views per year

At BMC, research is always in progress.

Learn more biomedcentral.com/submissions 